\title{
Designing a SCAR molecular marker for monitoring Trichoderma cf. harzianum in experimental communities ${ }^{* \#}$
}

\author{
Gabriel PÉREZ, Valentina VERDEJO, Clarissa GONDIM-PORTO, Julieta ORLANDO, Margarita CARU' ${ }^{\dagger \neq}$ \\ (Department of Ecological Sciences, Faculty of Sciences, University of Chile, Santiago, Chile) \\ †E-mail: margarita_caru@yahoo.com
}

Received Mar. 3, 2014; Revision accepted July 22, 2014; Crosschecked Aug. 25, 2014

\begin{abstract}
Several species of the fungal genus Trichoderma establish biological interactions with various micro- and macro-organisms. Some of these interactions are relevant in ecological terms and in biotechnological applications, such as biocontrol, where Trichoderma could be considered as an invasive species that colonizes a recipient community. The success of this invasion depends on multiple factors, which can be assayed using experimental communities as study models. Therefore, the aim of this work is to develop a species-specific sequence-characterized amplified region (SCAR) marker to monitor the colonization and growth of $T$. cf. harzianum when it invades experimental communities. For this study, 16 randomly amplified polymorphic DNA (RAPD) primers of 10-mer were used to generate polymorphic patterns, one of which generated a band present only in strains of $T$. cf. harzianum. This band was cloned, sequenced, and five primers of 20-23 mer were designed. Primer pairs 2F2/2R2 and 2F2/2R3 successfully and specifically amplified fragments of 278 and $448 \mathrm{bp}$ from the $T$. cf. harzianum BpT10a strain DNA, respectively. Both primer pairs were also tested against the DNA from 14 strains of $T$. cf. harzianum and several strains of different fungal genera as specificity controls. Only the DNA from the strains of $T$. cf. harzianum was successfully amplified. Moreover, primer pair 2F2/2R2 was assessed by quantitative real-time polymerase chain reaction (PCR) using fungal DNA mixtures and DNA extracted from fungal experimental communities as templates. $T$. cf. harzianum was detectable even when as few as 100 copies of the SCAR marker were available or even when its population represented only $0.1 \%$ of the whole community.
\end{abstract}

Key words: Trichoderma cf. harzianum, Sequence-characterized amplified region (SCAR), Molecular marker, Experimental fungal communities doi: $10.1631 /$ jzus.B1400063

Document code: A

CLC number: Q93; Q78

\section{Introduction}

One of the major challenges in ecology is to understand which factors control the abundance and diversity of species, how these are influenced by natural or human-induced changes, and what are the consequences for ecosystem processes and properties (van der Putten et al., 2007). Experimental commu-

\footnotetext{
Corresponding author

* Project supported by the Chilean National Fund for Scientific and Technological Development (FONDECYT) (No. 1120508)

${ }^{*}$ Electronic supplementary materials: The online version of this article (http://dx.doi.org/10.1631/jzus.B1400063) contains supplementary materials, which are available to authorized users

(C) Zhejiang University and Springer-Verlag Berlin Heidelberg 2014
}

nities help answering some of these questions (Jessup et al., 2005) and are useful to explain the interactive processes between the microbiota of a complex ecosystem and the different environmental conditions (Moore et al., 1996). An area of growing interest is biocontrol, which can be studied in the context of biological invasions, since biocontrol isolates must be able to colonize and grow in a recipient community. In this context, Trichoderma species can be considered as invasive and their success as biocontrol agents will depend on abiotic factors such as availability of resources, or on biotic factors such as the properties of the recipient community as well as the ability of the invasive species to invade it (Savazzini et al., 2009; Zhang et al., 2013). Species of the genus Trichoderma 
(Family Hypocreaceae; Phylum Ascomycota) are ubiquitous in soil, where they may represent the majority of the fungal biomass (Druzhinina et al., 2011), and play important environmental roles, such as degradation of complex organic compounds and establishment of mutualistic interactions with plants (Kubicek et al., 2008). Likewise, Trichoderma spp. have been reported to act as biological control agents by their antagonistic properties towards fungal pathogens (Viterbo et al., 2001; Benítez et al., 2004; Harman, 2006; Komon-Zelazowska et al., 2007), being suggested that they are even able to attack, parasitize, and gain nutrition from other fungi, such as phytopathogens (Druzhinina et al., 2011).

There are a variety of mechanisms by which Trichoderma species establish interactions with other organisms; these can be direct, as the aforementioned mycoparasitism, in which Trichoderma species parasitize other fungi like those belonging to the genera Pythium, Phytophthora, Botrytis, Rhizoctonia, and Fusarium, some of which are well known disease agents of plants (Benítez et al., 2004; Harman, 2006). Another direct mechanism corresponds to amensalism, which is related to the production of antibiotics and peptaibols that directly affect other fungi, being able to act on a synergistic manner with mycoparasitism (Grondona et al., 1997; Benítez et al., 2004; Komon-Zelazowska et al., 2007). However, interactions can also be indirect, such as competition for nutrients and space, change of environmental conditions, and stimulation of the growth and/or the immune system of plants by endophytism, among others (Harman et al., 2004; Harman, 2006). Due to the relevance of Trichoderma species in terrestrial ecosystems and their ability to successfully colonize different habitats (Schuster and Schmoll, 2010; Kredics et al., 2014), a proper identification of Trichoderma strains is crucial for understanding how this fungus colonizes a recipient microbial community. Various procedures have been proposed and designed for monitoring Trichoderma strains, both in experimental and environmental communities, which range from their cultivation in selective media (Knudsen et al., 1996; Williams et al., 2003; VargasGil et al., 2009) to the genetic modification of such organisms (Green and Jensen, 1995). Another way of performing this monitoring is through the identification of the strain(s) or species by specific molecular markers (Hermosa et al., 2000; Druzhinina and $\mathrm{Ku}-$ bicek, 2005; Kubicek et al., 2008). In many cases, sequence-characterized amplified region (SCAR) markers have been developed by converting dominant randomly amplified polymorphic DNA (RAPD) fingerprints into specific molecular markers (Parasnis et al., 2000; Koveza et al., 2001; Arnedo-Andrés et al., 2002; Bautista et al., 2003; Rubio et al., 2005; Feng et al., 2011). The main aim of the present study was to develop a SCAR molecular marker to specifically detect some Trichoderma cf. harzianum strains for monitoring the colonization and growth of $T$. cf. harzianum when it invades experimental communities. This work is a part of a research project on biological invasions in which experimental fungal communities are used as study models to assess the biotic and abiotic factors determining the success of $T$. cf. harzianum as an invasive species.

\section{Materials and methods}

\subsection{Fungal samples and culture conditions}

Fourteen strains of filamentous fungi belonging to the genus Trichoderma were provided by Castillo (2009), labeled as BpT1a, BpT2, BpT5, BpT6, BpT7, BpT9, BpT10, BpT10a, BpTA, BpTC, BpTF, BpTH, BpTP, and BpTR (Table 1). From each sample, monosporic cultures were prepared from serial dilutions of an aqueous conidial suspension $(\mathrm{NaCl}$ $0.7 \mathrm{~g} / \mathrm{ml}$ ) derived from 7-d-old cultures, which were spread on potato dextrose agar (PDA; Difco ${ }^{\mathrm{TM}}$ ) medium. The plates were incubated at $25^{\circ} \mathrm{C}$ until single colonies were observed $(2-3 \mathrm{~d})$, which were then re-inoculated on PDA medium to ensure the purity of the culture (Gams and Bissett, 1998). In addition, 20 DNA samples were provided by Biopacific Co., Ltd. (Chile), 8 of which corresponded to $T$. cf. harzianum (1, 2, 3, 4, 6, 7, 8, and 9), 6 to Penicillium spp. (Atc4, Atc5, 9a, 9ar1, C1R, and C3F), 3 to Aspergillus spp. (HI, $\mathrm{HC1}$, and 4a), and the other 3 to Davidiella sp. (HM), Paecilomyces sp. (9ar), and Monascus sp. (Atc8) (Table 1). In addition, the fungal species Aspergillus niger (MR-1), Purpureocillium sp. (MR-6), Paecilomyces variotti (MR-9), Beauveria bassiana (MR-21), Talaromyces flavus (MR-25), and Cladosporium cladosporoides (MR-12) were obtained from the fungal collection of the laboratory of Microbial Ecology, Faculty of Sciences, University of Chile (Table 1). 
Table 1 Fungal strains and DNA samples used in this study

\begin{tabular}{|c|c|c|c|c|c|}
\hline Strain & Species & Origin & $\begin{array}{c}\text { ITS } \\
\text { accession } \\
\text { No. }\end{array}$ & $\begin{array}{l}\text { Most related } \\
\text { sequence } \\
\text { accession No. }\end{array}$ & $\begin{array}{c}\text { Identity } \\
(\%)\end{array}$ \\
\hline BpT1a & Trichoderma novaezelandiae & Neltume, Chile & KC812353 & AY154925 & $99(100)$ \\
\hline BpT2 & Trichoderma sp. & Neltume, Chile & KC812352 & $\mathrm{KC} 007277$ & $99(100)$ \\
\hline BpT5 & Trichoderma atroviride & Neltume, Chile & KC812350 & $\mathrm{KC} 171717$ & $99(96)$ \\
\hline BpT6 & Trichoderma cf. harzianum & Laja River, Chile & KC812342 & JX088246 & $100(100)$ \\
\hline ВpT7 & Trichoderma cf. harzianum & Laja River, Chile & KC812343 & JX088246 & $100(100)$ \\
\hline ВpT9 & Trichoderma atroviride & Laja River, Chile & KC812349 & $\mathrm{KC} 171717$ & $99(96)$ \\
\hline BpT10 & Trichoderma atroviride & Port Fuy, Chile & KC812348 & $\mathrm{KC} 171717$ & $99(96)$ \\
\hline BpT10a & Trichoderma cf. harzianum & Port Fuy, Chile & KC812341 & JN716380 & $100(100)$ \\
\hline BpTA & Trichoderma cf. harzianum & Neltume, Chile & KC812340 & JX416574 & $99(89)$ \\
\hline BpTC & T. atroviride & Port Fuy, Chile & KC812346 & $\mathrm{KC} 171717$ & $99(96)$ \\
\hline BpTF & Trichoderma cf. harzianum & Laja River, Chile & KC812345 & JX088246 & $100(100)$ \\
\hline BрTH & Trichoderma cf. harzianum & Port Fuy, Chile & KC812344 & JX088246 & $100(100)$ \\
\hline ВpTP & Trichoderma citrinoviride & Port Consuelo, Chile & KC812351 & JX173874 & $100(100)$ \\
\hline BpTR & Trichoderma atroviride & Laja River, Chile & KC812347 & $\mathrm{KC} 171717$ & $99(96)$ \\
\hline 1 & Trichoderma cf. harzianum & Biopacific Co., Ltd., Chile & KC812364 & JX416561 & $100(89)$ \\
\hline 2 & Trichoderma cf. harzianum & Biopacific Co., Ltd., Chile & KC812365 & JX088246 & $100(100)$ \\
\hline 3 & Trichoderma cf. harzianum & Biopacific Co., Ltd., Chile & KC812366 & JX416561 & $100(89)$ \\
\hline 4 & Trichoderma cf. harzianum & Biopacific Co., Ltd., Chile & KC812367 & JN716380 & $100(100)$ \\
\hline 6 & Trichoderma cf. harzianum & Biopacific Co., Ltd., Chile & KC812368 & AY605728 & $99(94)$ \\
\hline 7 & Trichoderma cf. harzianum & Biopacific Co., Ltd., Chile & KC812369 & JX416561 & $100(89)$ \\
\hline 8 & Trichoderma cf. harzianum & Biopacific Co., Ltd., Chile & KC812370 & JX644593 & $99(98)$ \\
\hline 9 & Trichoderma cf. harzianum & Biopacific Co., Ltd., Chile & KC812371 & JX416574 & $99(89)$ \\
\hline Atc 4 & Penicillium sp. & Biopacific Co., Ltd., Chile & KC812357 & JX869567 & $100(100)$ \\
\hline Atc5 & Penicillium sp. & Biopacific Co., Ltd., Chile & KC812358 & JX406503 & $100(100)$ \\
\hline $9 \mathrm{a}$ & Penicillium sp. & Biopacific Co., Ltd., Chile & KC812359 & FJ025212 & $100(100)$ \\
\hline 9ar1 & Penicillium sp. & Biopacific Co., Ltd., Chile & KC812360 & JN585940 & $100(100)$ \\
\hline $\mathrm{C} 1 \mathrm{R}$ & Penicillium sp. & Biopacific Co., Ltd., Chile & NA & NA & NA \\
\hline $\mathrm{C} 3 \mathrm{~F}$ & Penicillium sp. & Biopacific Co., Ltd., Chile & NA & NA & NA \\
\hline $\mathrm{HC} 1$ & Aspergillus sp. & Biopacific Co., Ltd., Chile & KC812355 & JQ316527 & $99(100)$ \\
\hline $\mathrm{HI}$ & Aspergillus sp. & Biopacific Co., Ltd., Chile & KC812356 & HМ061131 & $100(100)$ \\
\hline $4 a$ & Aspergillus sp. & Biopacific Co., Ltd., Chile & KC812354 & FR670319 & $100(100)$ \\
\hline $\mathrm{HM}$ & Davidiella $\mathrm{sp}$. & Biopacific Co., Ltd., Chile & KC812361 & JF911765 & $100(100)$ \\
\hline 9ar & Paecilomyces sp. & Biopacific Co., Ltd., Chile & KC812362 & GU980015 & $100(100)$ \\
\hline Atc 8 & Monascus sp. & Biopacific Co., Ltd., Chile & KC812363 & JN942665 & $100(100)$ \\
\hline MR- $1^{* *}$ & Aspergillus niger & El Romeral, Chile & NA & NA & NA \\
\hline MR-9** & Paecilomyces variotti & El Romeral, Chile & NA & NA & NA \\
\hline $\mathrm{MR}-21^{* *}$ & Beauveria bassiana & El Romeral, Chile & NA & NA & NA \\
\hline MR- $6^{* *}$ & Purpureocillium sp. & El Romeral, Chile & NA & NA & NA \\
\hline MR-25** & Talaromyces flavus & El Romeral, Chile & NA & NA & NA \\
\hline MR-12 $2^{* *}$ & Cladosporium cladosporoides & El Romeral, Chile & NA & NA & NA \\
\hline
\end{tabular}

${ }^{*}$ Most related sequence retrieved by BLAST using as query the ITS1-5.8S rDNA-ITS2 region of the samples. ${ }^{* *}$ Strains from the Fungal Collection of the Microbial Ecology Laboratory, Faculty of Sciences, University of Chile. NA: not available 
2.2 DNA extraction, polymerase chain reaction (PCR) amplification, and sequencing

Genomic DNA (gDNA) was extracted from fresh monosporic mycelia using the PowerSoil ${ }^{\mathrm{TM}}$ DNA extraction kit (MoBio Laboratories Inc.) according to the manufacturer's instructions. The quality and integrity of the extracted DNA were visualized in $0.8 \%(8 \mathrm{~g} / \mathrm{L})$ agarose gels in $1 \times$ TAE buffer (40 mmol/L Tris-acetate, $1 \mathrm{mmol} / \mathrm{L}$ EDTA $(\mathrm{pH} 8.0)$ ) stained with GelRed ${ }^{\mathrm{TM}}$ (Biotium). All DNA samples were stored at $-20{ }^{\circ} \mathrm{C}$ until analysis. A fragment corresponding to the 5.8S ribosomal RNA (rRNA) gene and the two ribosomal internal transcribed spacers (ITS1 and ITS2) of the ribosomal region were amplified by PCR using primers ITS1 (5'-TCCGTA GGTGAACCTGCGG-3') and ITS4 (5'-TCCTCC GCTTATTGATATGC-3') (White et al., 1990).

The amplifications were carried out in a total volume of $25 \mu$ l containing $1 \mu \mathrm{l}$ of gDNA $(20 \pm 5) \mathrm{ng}$, with primers at a concentration of $400 \mathrm{nmol} / \mathrm{L}$ each, and the reagents provided in the GoTaq ${ }^{\circledR}$ Green Master Mix (Promega, USA; GoTaq ${ }^{\circledR}$ DNA polymerase in $1 \times \mathrm{Green}_{\mathrm{GoTaq}}{ }^{\circledR}$ reaction buffer $(\mathrm{pH} \mathrm{8.5)}$ ), $200 \mu \mathrm{mol} / \mathrm{L}$ of each dNTP, and $1.5 \mathrm{mmol} / \mathrm{L} \mathrm{MgCl}$ ). The thermal cycles consisted of 3 min of initial denaturation at $94{ }^{\circ} \mathrm{C}, 37$ cycles of denaturation at $94{ }^{\circ} \mathrm{C}$ for $30 \mathrm{~s}$, then $30 \mathrm{~s}$ annealing at $55^{\circ} \mathrm{C}$ and $3 \mathrm{~min}$ extension at $72{ }^{\circ} \mathrm{C}$, and a final extension of $20 \mathrm{~min}$ at $72{ }^{\circ} \mathrm{C}$ on a MaxyGene thermocycler (Axygen). PCR products were evaluated on $1.2 \%(12 \mathrm{~g} / \mathrm{L})$ agarose gels, with the conditions above mentioned using the $100 \mathrm{bp}$ (Invitrogen) as the molecular weight marker. Amplicons were sequenced (Macrogen Inc., Seoul, Korea) using a Genetic Analyzer 3730XL (Applied Biosystems). The identity of each sequence was assessed using the Basic Local Alignment Search Tool (BLAST) (Altschul et al., 1990). In addition, all sequences belonging to the genus Trichoderma were identified by TrichOKEY 2.0 (Druzhinina et al., 2005).

\subsection{RAPD}

To carry out RAPD analyses, 16 arbitrary 10-mer primers (Operon, USA) were tested against purified gDNA from different Trichoderma species, including some $T$. cf. harzianum strains, and nonTrichoderma DNA samples from the genera Asper- gillus, Penicillium, and Monascus (HI, Atc4, and Atc8 strains, respectively). The PCR reactions were performed as mentioned above. The thermal cycling was as described by Lehmann et al. (1992), consisting of an initial denaturation of $5 \mathrm{~min}$ at $94{ }^{\circ} \mathrm{C}$, followed by 45 cycles of $1 \mathrm{~min}$ at $94{ }^{\circ} \mathrm{C}, 1 \mathrm{~min}$ at $36^{\circ} \mathrm{C}, 2 \mathrm{~min}$ at $72{ }^{\circ} \mathrm{C}$, and a final extension of $10 \mathrm{~min}$ at $72{ }^{\circ} \mathrm{C}$, using a MaxyGene thermocycler (Axygen). PCR products were analyzed by electrophoresis in $1.5 \%(15 \mathrm{~g} / \mathrm{L})$ agarose gels using the above mentioned conditions.

\subsection{Cloning and sequencing of an RAPD amplicon}

The band of interest identified in the RAPD analysis (Fig. 1) was gel-excised and purified using the Wizard SV Gel and PCR Clean-Up system kit (Promega), ligated to the pTZ-57R/T vector (Fermentas) and then transformed into Escherichia coli using the InsTA clone PCR cloning kit (Fermentas). The transformants were grown in Luria-Bertani (LB) medium and selected by their resistance to ampicillin $(50 \mu \mathrm{g} / \mathrm{ml})$ and their inability to hydrolyze X-Gal (5-bromo-4-chloro-3-indolyl- $\beta$-D-galactopyranoside) in the presence of isopropylthio- $\beta$-galactoside (IPTG). The presence of the expected size insert was confirmed by colony-PCR using primers M13F (5'-GTA AAACGACGGCCAG-3') and M13R (5'-CAGGAA ACAGCTATGACC-3').

The amplified product was sequenced (Macrogen Inc., Seoul, Korea) in both directions using a Genetic Analyzer 3730XL (Applied Biosystems). The sequencing result was edited and subsequently evaluated using BLAST-n (Altschul et al., 1990) to determine whether this sequence had some identity with any of the known sequences present in the GenBank database of the National Center for Biotechnology Information (NCBI) (Benson et al., 2013). Finally, a local BLAST of this sequence with the genome of $T$. harzianum CBS 226.95 available at the Doe Joint Genome Institute web page (http://genome. jgi.doe.gov/) was performed to determine the number of copies of the SCAR marker.

\subsection{Design of SCAR primers}

The SCAR primers were designed using the NCBI primer-BLAST tool, which uses the Primer3 tool (Rozen and Skaletsky, 1999). Five primers were designed: two forward primers $(2 \mathrm{~F} 1$ and $2 \mathrm{~F} 2)$ and 
three reverse primers (2R1, 2R2, and 2R3) (Table 2). To evaluate these primers and to define the PCR annealing temperature, DNA from $T$. cf. harzianum BpTF was used as the template. The conditions of the reagents were the same as in the above mentioned amplification protocols, except that the concentration of each primer was $200 \mathrm{nmol} / \mathrm{L}$. The thermal cycling was as follows: initial denaturation of $3 \mathrm{~min}$ at $94{ }^{\circ} \mathrm{C}$, followed by 30 cycles of 1 min denaturation at $94{ }^{\circ} \mathrm{C}$, $1 \mathrm{~min}$ annealing, where the temperature ranged between 40 and $64{ }^{\circ} \mathrm{C}, 1 \mathrm{~min}$ extension at $72{ }^{\circ} \mathrm{C}$, and a final extension of $7 \mathrm{~min}$ at $72{ }^{\circ} \mathrm{C}$. Once the thermal cycling conditions were assessed, the primers were evaluated using 22 DNA samples from Trichoderma belonging to five different species in addition to DNA from species of the genera Penicillium, Aspergillus, Davidiella, Paecilomyces, and Monascus.

\subsection{Real-time quantitative PCR (qPCR) assays}

Primers $2 \mathrm{~F} 2$ and $2 \mathrm{R} 2$ were additionally tested in real-time qPCR assays. Reactions were carried out in

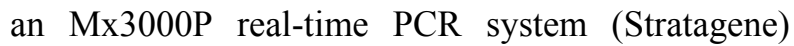
using the GoTaq $^{\circledR}$ Real-Time qPCR Master Mix (Promega). All reactions were performed in a total volume of $20 \mu \mathrm{l}$, with $0.3 \mu \mathrm{mol} / \mathrm{L}$ of each primer and $1 \mu 1$ of template DNA at the concentrations required by each assay. The thermal cycling was as follows: 2 min of denaturation at $95^{\circ} \mathrm{C}, 40$ cycles consisting of $15 \mathrm{~s}$ denaturation at $95^{\circ} \mathrm{C}$, then $1 \mathrm{~min}$ annealing at $64{ }^{\circ} \mathrm{C}$ and 1 min extension at $72{ }^{\circ} \mathrm{C}$.

To quantify the number of SCAR copies specifically detected by the primers evaluated by realtime qPCR, three standard curves in quadruplicate were performed using 10 -fold serial dilutions of

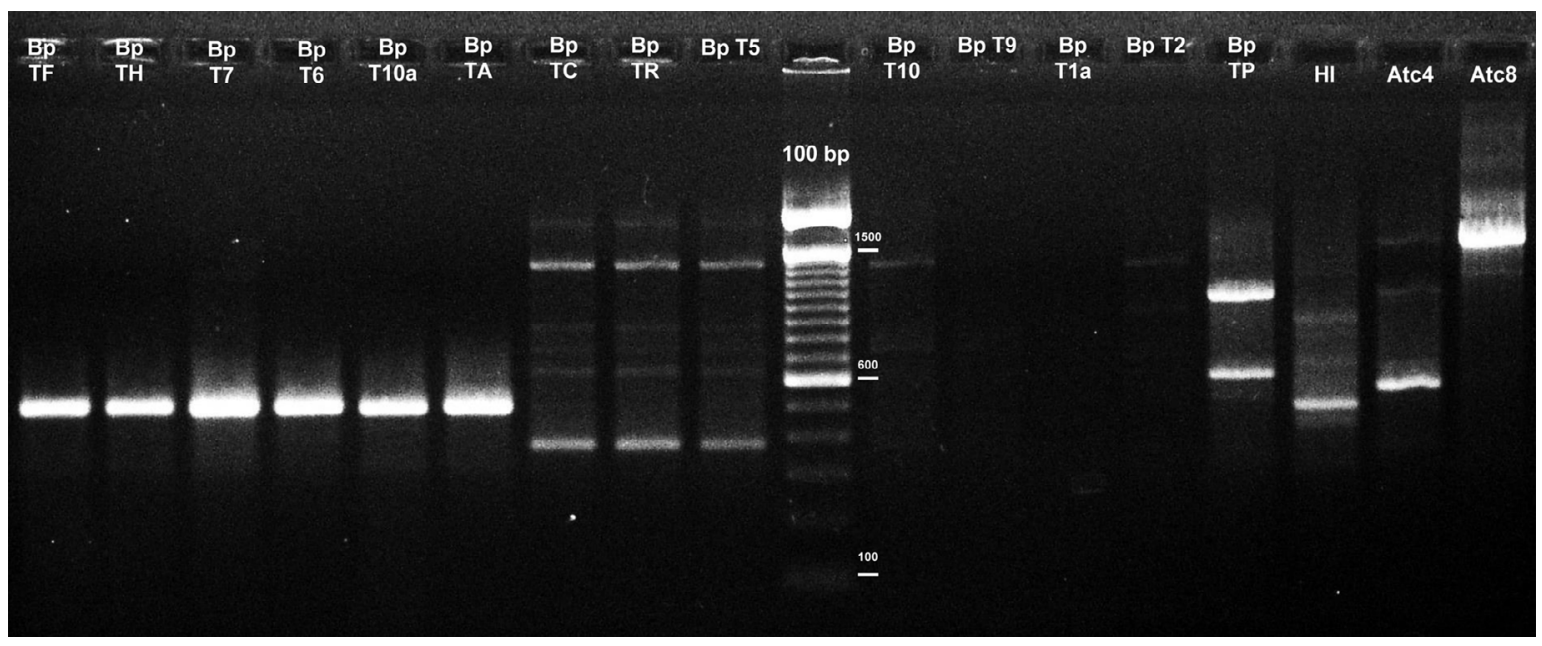

Fig. 1 RAPD fingerprintings of fungal species

Agarose gel showing the RAPD banding profile amplified from fungal gDNA using the OPX02 primer. Lanes labeled as BpTF, BpTH, BpT7, BpT6, BpT10a, and BpTA correspond to isolates of T. cf. harzianum; BpTC, BpTR, BpT5, and BpT10, BpT9 of T. atroviride; BpT1a of T. novaezelandiae; BpT2 of Trichoderma sp.; BpTP of T. citrinoviride; HI of Aspergillus sp.; Atc4 of Penicillium sp.; and, Atc8 of Monascus sp. (Table 1). The 100-bp ladder was used as a molecular weight marker

Table 2 Characteristics of the designed SCAR primers

\begin{tabular}{clccc}
\hline SCAR primer & \multicolumn{1}{c}{ Sequence $\left(5^{\prime} \rightarrow 3^{\prime}\right)$} & Position in the RAPD fragment $(\mathrm{bp})$ & GC $(\%)$ & $T_{\mathrm{m}}\left({ }^{\circ} \mathrm{C}\right)$ \\
\hline 2F1 & TCCGCCACCATCTAGACCAATCG & $2-23$ & 56.5 & 58.28 \\
2F2 & TGGCTCGTCGTAGTTCGGAGAAG & $51-73$ & 56.5 & 58.26 \\
2R1 & CCACCGCGGGATTCATGCACT & $474-494$ & 65.0 & 58.68 \\
2R2 & CCAGATCGGCCACCGAAGAAAC & $307-328$ & 59.1 & 57.92 \\
2R3 & GCCACCCACCGCGGGATTCA & $480-499$ & 70.0 & 61.78 \\
\hline
\end{tabular}

GC: guanine-cytosine; $T_{\mathrm{m}}$ : melting temperature 
different DNA templates $\left(1-10^{-5} \mathrm{ng}\right)$ : (1) gDNA of T. cf. harzianum BpT10a, (2) a linearized plasmid (pTZ57R/T) containing the SCAR marker, and (3) an equimolar mix of fungal gDNA from several species (P. canescens [MR-13], A. niger [MR-1], C. cladosporoides [MR-12], P. variotii [MR-9], and T. flavus [MR-25]). The SCAR copy numbers were determined using the proportion between the nucleotide mass and the nucleotide number according to the ratio 1.096× $10^{-21} \mathrm{~g} / \mathrm{bp}$; besides, the sizes of the T. harzianum CBS 226.95 genome $(40.98 \mathrm{Mbp})$ and the plasmid with the SCAR sequence (3164 bp) were also considered. The threshold cycle $\left(C_{\mathrm{t}}\right)$ of each 10 -fold serial dilution reaction was plotted versus the number of SCAR copies expressed as log. Using a linear regression analysis, the slope and the determination coefficients $\left(r^{2}\right)$ of the three assays were calculated. In addition, the percentage of efficiency was obtained for each of the three standard curves according to: efficiency $=\left(10^{-1 / \text { slope }}-1\right) \times 100 \%$.

The sensibility of the SCAR primers to detect $T$. cf. harzianum by qPCR was assessed by using 10 -fold serial dilutions of the aforementioned DNA templates In the latter case, in addition to the equimolar gDNA mix from the five fungal species, six additional mixes were made, where $T$. cf. harzianum gDNA was present in decreasing percentages $(10 \%, 5 \%, 2 \%, 1 \%$, $0.2 \%$, and $0.1 \%$ ). The six assays were replicated four times under the same reaction conditions as above mentioned.

Finally, the SCAR primers were evaluated in two experimental fungal communities inoculated with $T$. cf. harzianum, where its colonization and growth were monitored by qPCR. The experimental communities were set up in $20 \mathrm{ml}$ flasks using $1 \mathrm{~g}$ of rock wool as a support matrix soaked with Vogel medium (supplemented with yeast extract $0.5 \%$, dextrose $0.5 \%$, and chloramphenicol $30 \mu \mathrm{g} / \mathrm{ml}$ ) to reach $60 \%$ of the water-holding capacity (WHC). Experimental communities were assembled in duplicates and consisted of the following: Community 1 was composed of $T$. citrinoviride (BpTP), T. novaezelandiae (BpT1a), T. atroviride (Bpt10), B. bassiana (MR-21), and Purpureocillium sp. (MR-6); and Community 2 was composed of $P$. canescens (MR-13), A. niger (MR-1), C. cladosporoides (MR-12), P. variotii (MR-9), and T. flavus (MR-25).

Each community was inoculated with $2 \times 10^{4}$ spores of each fungal isolate and incubated at $25^{\circ} \mathrm{C}$; after $3 \mathrm{~d}$ they were inoculated with $2 \times 10^{4}$ spores of $T$. cf. harzianum BpT10a. Fungal experimental communities without $T$. cf. harzianum BpT10a were built in duplicate as controls. Destructive samplings were carried out $0,3,7$, and $10 \mathrm{~d}$ after inoculation with $T$. cf. harzianum BpT10a and the gDNA was extracted with the PowerSoil ${ }^{\mathrm{TM}}$ DNA extraction kit (MoBio Laboratories Inc.). gDNA was quantified using the Take3 ${ }^{\text {TM }}$ Epoch MicroVolume Plate reader (Biotek) and $1 \mathrm{ng}$ was used as the template for the qPCR reactions, which were performed under the same conditions above mentioned. The fungal gDNAmix standard curve was used to calculate the copy number of the SCAR marker in each community.

\section{Results}

\subsection{Molecular identification of fungal strains}

All fungal strains and DNA samples were identified by amplification and sequencing of the molecular marker ITS1-5.8S rDNA-ITS2 and the subsequent search, by means of BLAST-n, in databases from NBCI and the barcode tool for Trichoderma (TrichOKEY2.0) (Druzhinina et al., 2005) when possible. The sequences of the isolates were related with nine different genera (Trichoderma, Penicillium, Aspergillus, Davidiella, Paecilomyces, Monascus, Beauveria, Talaromyces, and Cladosporium) confirming all the previous identifications (Table 1).

\subsection{SCAR marker design}

The SCAR marker for T. cf. harzianum was designed through an RAPD assay. The amplicons obtained ranged between 200 and $2350 \mathrm{bp}$, resulting in highly polymorphic patterns for some of the used primers. However, for the design of the SCAR marker, only those amplicons with high intensity and reproducibility were considered. Using the primer OPX-02, a band of approximately $500 \mathrm{bp}$ was detected, which was common to all the $T$. cf. harzianum strains (Figs. 1 and S1). This band of interest was gel-excised and purified from the T. cf. harzianum BpTF isolate; then it was cloned into the $\mathrm{pTZ} 57 \mathrm{R} / \mathrm{T}$ vector and transformed into E. coli. Five transformants were selected and the insert was recovered using the M13 primers, obtaining a fragment of about $650 \mathrm{bp}$. The 
amplicons were sequenced in both directions using the primers M13F and M13R. The sequences were edited (vector sequences were removed) leaving only the fragment of interest, which resulted in a sequence of 503 nucleotides (Fig. S2). A BLAST-n analysis of this sequence showed no identity with any other sequences in GenBank. Furthermore, the local BLAST analysis performed against the $T$. harzianum CBS 226.95 genome showed that it was present in a single copy (Table S1). Based on the DNA sequence of the cloned 503-bp fragments (FASTA S1), SCAR primers were designed, including the primer sequences initially used for the RAPD analyses. Next, internal primer pairs were designed for reaching better amplification results. The primer positions are shown in Fig. S2.

By means of an in silico evaluation of the primers, their sequences, GC (guanine-cytosine) contents, $T_{\mathrm{m}}$ (melting temperature) values, and positions in the RAPD sequenced fragment were determined (Table 2).

\subsection{SCAR marker evaluation}

SCAR primers were evaluated using a gradient of annealing temperatures, with the gDNA from $T$. cf. harzianum BpTF as the template. The SCAR primers were evaluated using different combinations of them. Two primer combinations, 2F2/2R2 and 2F2/2R3, generated an intense band of the expected size in the whole tested temperature range $\left(40-64^{\circ} \mathrm{C}\right)$. To avoid non-specific amplification, the higher annealing temperature was chosen to carry out subsequent assays. The other primer combinations did not yield any amplification products and no non-specific bands were obtained. PCR reactions were conducted using gDNA from all the Trichoderma isolates included in Table 1, along with the gDNA corresponding to species of the genera Penicillium (Atc4, Atc5, 9a, 9ar1, $\mathrm{C} 1 \mathrm{R}$, and $\mathrm{C} 3 \mathrm{~F}$ ), Aspergillus (HI, HC1, and 4a), Davidiella (HM), Paecilomyces (9ar), Monascus (Atc8), and a mixture of species from a compost sample (C3R). Primer pair 2F2/2R2 amplified only the 278-bp expected product from the $14 T$. $\mathrm{cf}$. harzianum DNA samples (Fig. 2), and no amplifications were obtained from the other non-Trichoderma species. Similar results were observed with the primer pair 2F2/2R3, which generated the 448-bp expected amplified product in all the reactions where $T$. cf. harzianum DNA was used as the template (Fig. S3).
Therefore, both primers were suitable for amplifying the SCAR marker by conventional PCR; however, in the case of the qPCR primer pair, 2F2/2R2 was preferred because it yielded the shortest fragment.

Using the database available at http://genome.jgi. doe.gov/, the SCAR sequence was aligned with 366 fungal genomes, and no hit was observed with non-Trichoderma fungi. In the Trichoderma group, six genomes were available, and no alignment was detected with $T$. asperellum, T. atroviride, or $T$. longibrachiatum. In the case of $T$. harzianum CBS 226.95, as expected, the alignment reported a unique match of $220 \mathrm{bp}$, indicating that the SCAR marker is present in one copy in this genome. On the other hand, from the two available $T$. reesei genomes, only a 28-bp match with the SCAR sequence was detected, but this was not coincident with the areas where the primers were expected to anneal. Similarly, in the case of $T$. virens genome, a 99-bp match was found, but it did not include the annealing region for the $2 \mathrm{~F} 2$ primer (Table S1). Additionally, the SCAR marker from the tested $T$. cf. harzianum strains was sequenced to evaluate its variability (Fig. S4). The fulllength of the fragments matched, showing only 10 polymorphic sites, the most variable strain being the one of $T$. cf. harzianum BpT10a (FASTA S2). Moreover, the SCAR marker variability was compared with that of other markers, such as calmodulin (cal1) and translation elongation factor (tefl) genes, each one exhibiting a similar tree topology (Figs. S4 and S5).

\subsection{Real-time qPCR}

Primer pair 2F2/2R2 was used for the real-time qPCR assays. Only in the qPCR reactions where $T$. cf. harzianum DNA was used as template, was a signal $\left(C_{\mathrm{t}}\right)$ detected and a single melting peak observed (data not shown), which indicates that the primers were specific for the SCAR marker of $T$. cf. harzianum. These results were further checked using electrophoresis in agarose gels, in which only the expected size fragment was observed. In the three standard curves performed using 10-fold serial dilutions of different DNA templates: (1) gDNA of $T$. cf. harzianum BpT10a, (2) a linearized plasmid containing the SCAR marker, and (3) an equimolar mix of fungal gDNA from several species, qPCR reactions with similar levels of efficiency were reached (Fig. 3). The efficiency of each curve and $r^{2}$ values of regression 


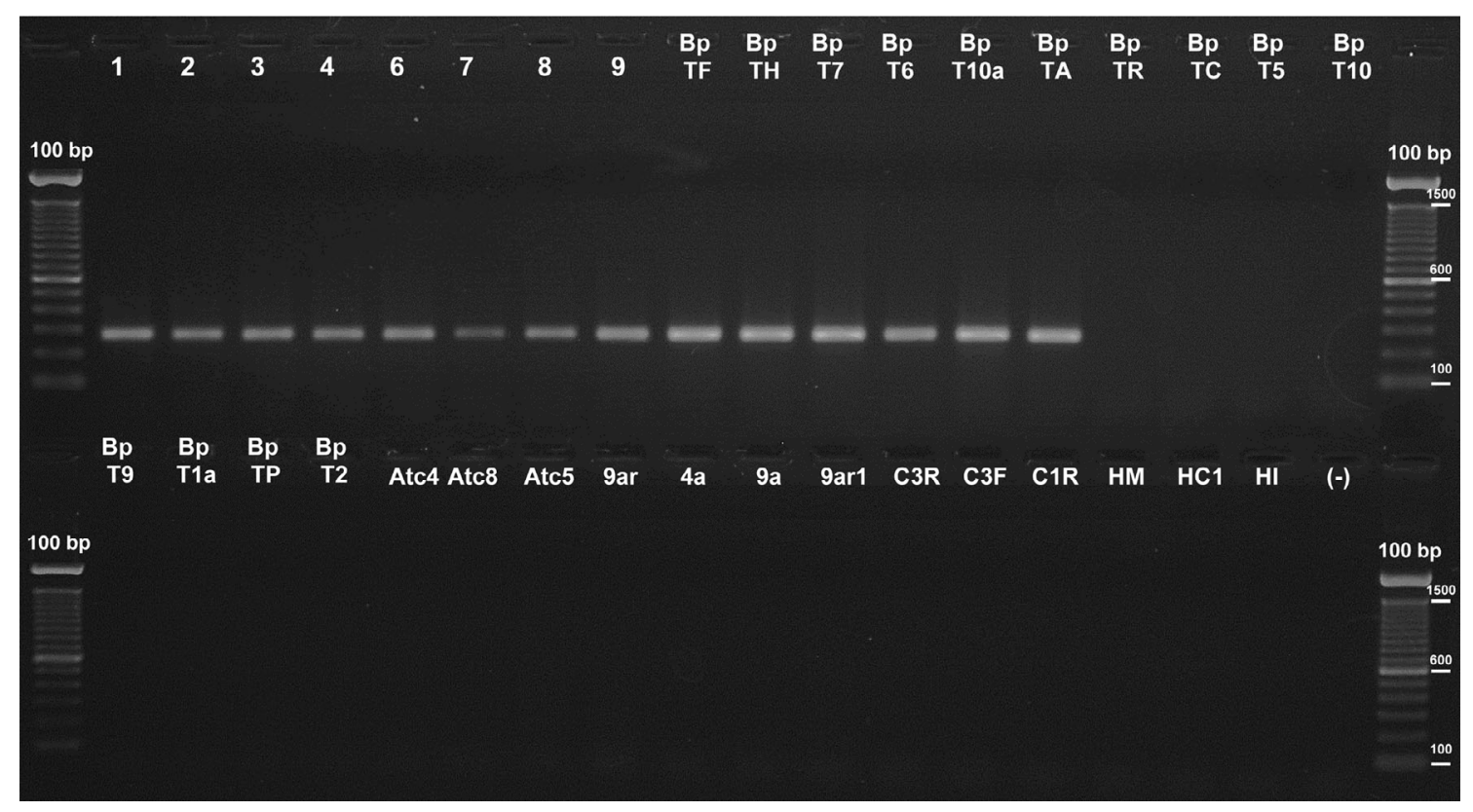

Fig. 2 Evaluation of the SCAR marker primers by PCR

The 278-bp fragments amplified from different $T$. harzianum strains using the SCAR 2F2 and 2R2 primers are shown in the agarose gel together with the absence of amplification from other fungal species. Lanes labeled as 1, 2, 3, 4, 6, 7, 8, 9, BpTF, BpTH, BpT7, BpT6, BpT10a, and BpTA correspond to gDNA from T. cf. harzianum isolates; BpTR, BpTC, BpT5, BpT10, and BpT9 from T. atroviride; BpT1a from T. novaezelandiae; BpTP from T. citrinoviride; BpT2 from Trichoderma sp.; Atc4, Atc5, 9a, 9ar1, C1R, and C3F from Penicillium spp.; HI, HC1, and 4a from Aspergillus spp.; HM from Davidiella sp.; 9ar from Paecilomyces sp.; Atc8 from Monascus sp. (see Table 1 for details); and C3R from a compost sample. (-) is a negative control. As a molecular weight marker the 100-bp ladder was used

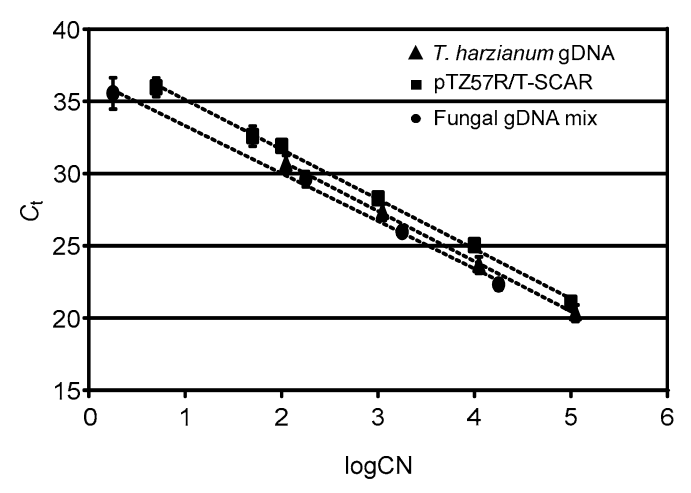

\begin{tabular}{lccc}
\hline \multicolumn{1}{c}{ Template } & Linear regression & $r^{2}$ & $\begin{array}{c}\text { Efficiency } \\
(\%)\end{array}$ \\
\hline T. harzianum gDNA & $C_{\mathrm{t}}=-3.4667 \log \mathrm{CN}+37.795$ & 0.9996 & 94 \\
pTZ57R/T-SCAR & $C_{\mathrm{t}}=-3.4417 \log \mathrm{CN}+38.544$ & 0.9983 & 95 \\
Fungal gDNA mix & $C_{\mathrm{t}}=-3.2991 \log \mathrm{CN}+36.607$ & 0.9967 & 101 \\
\hline
\end{tabular}

Fig. 3 Evaluation of SCAR marker primers by real-time quantitative PCR (qPCR)

The SCAR primers were evaluated by qPCR in three different contexts: $T$. cf. harzianum gDNA, a plasmid with the SCAR fragment, and a mix of fungal gDNA. For the three assays, the linear regression, $r^{2}$, and the efficiency of the reaction were calculated. $C_{\mathrm{t}}$ : threshold cycle; $\mathrm{CN}$ : copy number curves are shown in Fig. 3. In all the three standard curves, the linear regressions showed that the target SCAR fragment was detected even when the template included less than 100 copies of the target genome.

The sensibility of the SCAR marker for monitoring $T$. cf. harzianum BpT10a in a fungal DNA mix was evaluated, and the results showed that it was possible to detect $T$. cf. harzianum even at the lowest dilution tested, which represented $0.1 \%$ of the total gDNA used for the qPCR reactions.

Finally, the SCAR marker sensibility was also assayed in the two experimental fungal communities. In both communities, $T$. cf. harzianum BpT10a was detected, but at 7 and $10 \mathrm{~d}$ after inoculation, respectively. The SCAR copy numbers in Community 2 were 100 times higher than those in Community 1 (Fig. 4). In this community context, when the DNA was extracted $2 \mathrm{~h}$ after the inoculation of spores from T. cf. harzianum BpT10a (0 d), the SCAR primers were only able to detect $1 \%$ of the expected SCAR copy numbers assuming that each spore contains one genome. In Community 1 , the copy number showed 


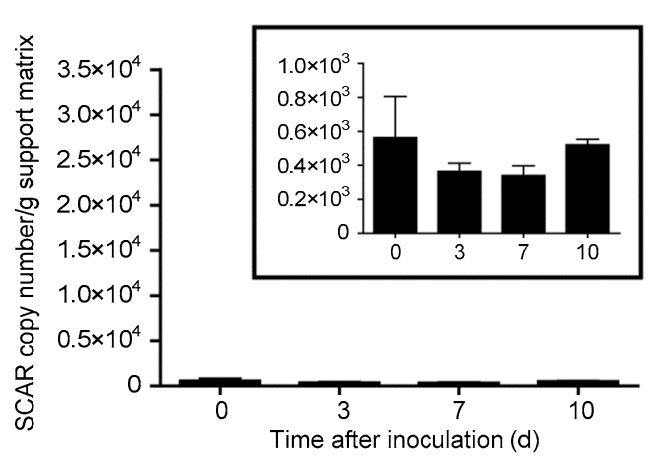

(a)

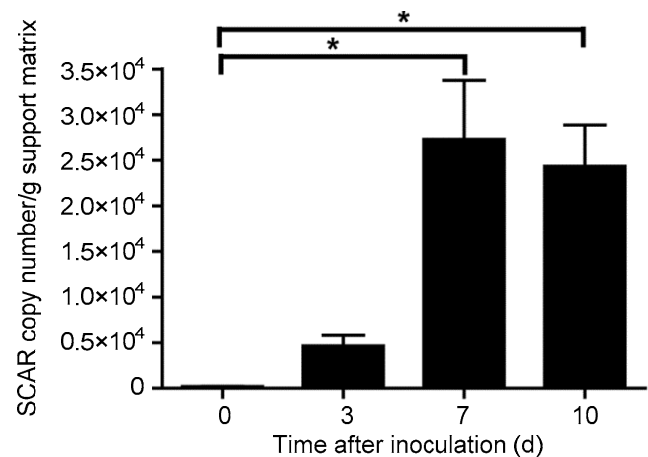

(b)

Fig. 4 SCAR marker copy numbers in experimental fungal communities at the different sampling time $T$. cf. harzianum was monitored by qPCR with the SCAR primers after inoculating it in two experimental fungal communities. (a) Community 1 composed of T. citrinoviride (BpTP), T. novaezelandiae (BpT1a), T. atroviride (Bpt10), B. bassiana (MR-21), and Purpureocillium sp. (MR-6); (b) Community 2 composed of $P$. canescens (MR-13), A. niger (MR-1), C. cladosporoides (MR-12), P. variotii (MR-9), and T. flavus (MR-25). Data are shown mean and standard deviation of duplicate measures. ${ }^{*}$ represents significantly different values according to the Tukey HSD test $(P \leq 0.05)$. The inset in the graph of Community 1 is included to show a higher resolution of the scale

no significant differences $(P=0.5717)$ during the whole incubation time, indicating that the fungus is able to stay in this community, but not successfully colonize; in Community 2, the population of $T$. cf. harzianum significantly increased after $10 \mathrm{~d}$ of incubation $(P=0.0189)$. No signals were detected in the control communities.

\section{Discussion}

RAPD analysis has been a very useful fingerprinting technique for studying DNA polymorphisms in various organisms, among them fungal strains, although methodological difficulties such as reproducibility and co-dominance are some of the disadvantages associated with this method. To overcome this situation, RAPD assays can be made more robust by converting them into a PCR-based in more specific and reliable markers known as SCAR. These molecular markers facilitate the detection and monitoring process by being able to directly evaluate the presence of species, strains, or isolates in complex environmental samples or experimental microbial assemblages. In this work, an RAPD marker was converted into a SCAR marker to develop a sensitive and reliable assay for monitoring $T$. cf. harzianum in experimental fungal communities. Based on the sequence data of the cloned RAPD fragment, specific primer pairs were designed and evaluated to amplify SCAR markers. Two species-specific primer pairs, 2F2/2R2 and 2F2/2R3, amplified a 278-bp and 448-bp DNA fragment, respectively, when tested using the gDNA from various strains of $T$. cf. harzianum. The specificity of the SCAR primer pairs was empirically checked using DNA extracted from various fungal species and from fungal experimental communities as templates; T. cf. harzianum was distinguished from all the other tested Trichoderma species by generating the expected amplification product. The alignments of the SCAR marker sequences amplified with the 2F2/2R2 primer set from the tested $T$. cf. harzianum strains showed a high homology. Moreover, the SCAR sequence variability of $T$. cf. harzianum strains used in this study was similar to those of call and tefl genes according to the neighbor-joining (NJ) tree topologies.

The SCAR sequence was also compared with 366 fungal genomes, and no significant sequence homology was observed with fungi belonging to genera different to Trichoderma. In the Trichoderma group, six genomes were actually available, and no alignment was found with $T$. asperellum, $T$. atroviride, or $T$. longibrachiatum. In the case of the T. reesei and $T$. virens genomes, partial matches were detected, but these were not coincident with the areas where the primers were expected to anneal.

According to the sequence alignment data, this marker is present only once in the T. harzianum CBS 226.95 genome, therefore allowing it to assess a quantitative detection, by qPCR, of the number of 
genomic units present in a complex sample and to study the dynamics of a population of $T$. cf. harzianum in an experimental fungal community.

Although the SCAR marker designed in this study was not able to discriminate among different $T$. cf. harzianum strains, it is highly sensitive, with a detection limit of at least 100 genome copies per nanogram of total DNA, being more sensitive than other reported SCAR markers (Rubio et al., 2005; Cordier et al., 2007). In addition, this SCAR marker is sensible enough to detect $T$. cf. harzianum representing $0.1 \%$ in $1 \mathrm{ng}$ of gDNA mix. This SCAR marker was also probed in fungal experimental communities, where the copy numbers determined by qPCR in a community composed of fungal species closely related to $T$. cf. harzianum BpT10a (Community 1) was not statistically different during the sampling time. Conversely, in Community 2, which comprised fungal species not as closely related to $T$. cf. harzianum BpT10a, its colonization was more successful, increasing the SCAR copy numbers from $7 \mathrm{~d}$ after inoculation. This result is in line with some previous studies and suggests that the composition of the recipient community affects the colonization by the alien fungus (Bae and Knudsen, 2001; 2005). Interactions, such as competition and amensalism, and the organic nutrient sources are reported to affect the populations and activities of biocontrol agents in the soil (Hoitink and Boehm, 1999). Moreover, in the experimental communities at $0 \mathrm{~d}$ after $T$. cf. harzianum BpT10a inoculation, the SCAR marker detected only $1 \%$ of the expected SCAR copy numbers, assuming that each spore in the inoculum contains one genome, which confirms that the DNA extraction methods for different sample types (spores, mycelia, support matrix, soil, etc.) could lead to underestimating the actual population of the fungus (Black and Foarde, 2007; Martin-Laurent et al., 2001).

SCAR markers derived from an RAPD assay have been used to detect different organisms at isolate or strain levels, such as Gliocladium catenulatum (Paavanen-Huhtala et al., 2000) and Fusarium oxysporum (del Mar Jiménez-Gascó and Jiménez-Díaz, 2003; Pasquali et al., 2006; Lievens et al., 2008). In addition, SCAR markers derived from an RAPD assay have been also previously reported and used to detect different Trichoderma species or strains in different samples with varying detection limits. Rubio et al. (2005) reported the specific detection, by means of a SCAR marker, of the T. harzianum 2413 strain both in a pure culture and an artificially inoculated sterile soil, but their specificity was not great enough to detect and quantify $T$. harzianum 2413 among a mixture of strains. Cordier et al. (2007) using a SCAR marker designed to specifically identify $T$. atroviride T1 strain monitored this strain in soil without crossdetection of other native populations of Trichoderma; the quantification of $T$. atroviride $\mathrm{T} 1$ by real-time PCR was possible at different fungal densities, even at the lowest concentration of $1 \times 10^{3}$ colony-forming unit (CFU) per gram of soil. Feng et al. (2011), using SCAR markers, quantified two Trichoderma biocontrol strains in artificially inoculated sterile soils by multiplex qPCR, which were found at approximately $10^{7}-10^{8}$ copies per gram of soil. SCAR markers have also been designed to detect Trichoderma at the genus level based in the ITS region sequence and used to detect and quantify Trichoderma spp. in different soils by real-time PCR (Hagn et al., 2007).

Other SCAR markers have been developed from sequences of endochitinase genes, for monitoring the biocontrol agent $T$. atroviride $\mathrm{SC} 1$ strain in field assays, with the detection limit $6 \times 10^{3}$ haploid genome copies per gram of soil (Savazzini et al., 2008), and from intergenic regions using universal primer combinations to distinguish the T. harzianum AS12-2 strain, without detection limits evaluated (Naeimi et al., 2011).

The design carried out in the present study focused on obtaining a molecular marker useful for a wide range of $T$. cf. harzianum strains, then allowing the invasion and colonization processes of this fungal species. These markers may be useful not only for monitoring the effect of Trichoderma in experimental communities, but could be also used as a quality control system to confirm the identity of $T$. cf. harzianum in the industrially batch production of this fungus to market it as a biocontrol agent. SCARbased real-time PCR has been successfully used to monitor biological control agents such as Aureobasidium pullulans L47 strain (Schena et al., 2002), Plectosphaerella cucumerina (Atkins et al., 2003), Candida oleophila (Massart et al., 2005), and Pseudomonas fluorescens (Pujol et al., 2005).

Eventually, these SCAR markers could be used to detect Trichoderma in environmental samples; 
however, since $T$. cf. harzianum is a cosmopolitan and diverse species, very frequent and abundant in soils, it is highly likely to find native strains very phylogenetically close to $T$. cf. harzianum, which could also be amplified with the designed primers. For this reason, this SCAR marker might not be useful for assessing the presence of $T$. cf. harzianum in environmental samples such as soil. In fact, it is very difficult to rule out cross-reactions with native strains not yet described and to discriminate between Trichoderma endogenous populations and those artificially inoculated, as has been reported by other authors in field trials (Feng et al., 2011). In any case, this SCAR marker can be used as a highly sensitive diagnostic tool, either by conventional PCR or qPCR, for tagging $T$. cf. harzianum populations in experimental fungal communities.

\section{Acknowledgements}

We appreciate the kindness of Mr. Pedro CASTILLO and Biopacific Co., Ltd. to facilitate the biological material. A careful and thorough review of the manuscript was provided by two anonymous reviewers; their constructive suggestions have strengthened the manuscript considerably and are appreciated. In addition, we are grateful to Dr. C. ZÚÑIGA (Faculty of Sciences, University of Chile) for the correction of the English language.

\section{Compliance with ethics guidelines}

Gabriel PÉREZ, Valentina VERDEJO, Clarissa GONDIMPORTO, Julieta ORLANDO, and Margarita CARÚ declare that they have no conflict of interest.

This article does not contain any studies with human or animal subjects performed by any of the authors.

\section{References}

Altschul, S.F., Gish, W., Miller, W., et al., 1990. Basic local alignment search tool. J. Mol. Biol., 215(3):403-410. [doi:10.1006/jmbi.1990.9999]

Arnedo-Andrés, M., Gil-Ortega, R., Luis-Arteaga, M., et al., 2002. Development of RAPD and SCAR markers linked to the Pvr4 locus for resistance to PVY in pepper (Capsicum annum L.). Theor. Appl. Genet., 105(6-7):10671074. [doi:10.1007/s00122-002-1058-2]

Atkins, S.D., Clark, I.M., Sosnowska, D., et al., 2003. Detection and quantification of Plectosphaerella cucumerina, a potential biological control agent of potato cyst nematodes, by using conventional PCR, real-time PCR, selective media, and baiting. Appl. Environ. Microbiol., 69(8): 4788-4793. [doi:10.1128/AEM.69.8.4788-4793.2003]

Bae, Y.S., Knudsen, G.R., 2001. Influence of a fungus-feeding nematode on growth and biocontrol efficacy of Trichoderma harzianum. Phytopathology, 91(3):301-306. [doi: 10.1094/PHYTO.2001.91.3.301]
Bae, Y.S., Knudsen, G.R., 2005. Soil microbial biomass influence on growth and biocontrol efficacy of Trichoderma harzianum. Biol. Control, 32(2):236-242. [doi:10. 1016/j.biocontrol.2004.10.001]

Bautista, R., Crespillo, R., Cánovas, F., et al., 2003. Identification of olive-tree cultivars with SCAR markers. Euphytica, 129(1):33-41. [doi:10.1023/A:1021528122049]

Benítez, T., Rincón, A.M., Limón, M.C., et al., 2004. Biocontrol mechanisms of Trichoderma strains. Int. Microbiol., 7:249-260.

Benson, D.A., Cavanaugh, M., Clark, K., et al., 2013. GenBank. Nucl. Acids Res., 41(D1):D36-D42. [doi:10.1093/ nar/gks1195]

Black, J.A., Foarde, K.K., 2007. Comparison of four different methods for extraction of Stachybotrys chartarum spore DNA and verification by real-time PCR. J. Microbiol. Meth., 70(1):75-81. [doi:10.1016/j.mimet.2007.03.017]

Castillo, P., 2009. Isolation and identification of strains of Trichoderma sp. natives of Chile. Evaluation of in vitro antagonism against Botrytis sp. Biologist Thesis. Catholic University of Valparaíso, Chile.

Cordier, C., Edel-Hermann, V., Martin-Laurent, F., et al., 2007. SCAR-based real time PCR to identify a biocontrol strain (T1) of Trichoderma atroviride and study its population dynamics in soils. J. Microbiol. Meth., 68(1):60-68. [doi:10.1016/j.mimet.2006.06.006]

del Mar Jiménez-Gascó, M., Jiménez-Diaz, R.M., 2003. Development of a specific PCR-based assay for the identification of Fusarium oxysporum f. sp. ciceris and its pathogenic races $0,1 \mathrm{~A}, 5$, and 6. Phytopathology, 93(2):200-209. [doi:10.1094/PHYTO.2003.93.2.200]

Druzhinina, I.S., Kubicek, C.P., 2005. Species concepts and biodiversity in Trichoderma and Hypocrea: from aggregate species to species clusters? J. Zhejiang Univ.-Sci. B, 6(2):100-112. [doi:10.1631/jzus.2005.B0100]

Druzhinina, I.S., Kopchinskiy, A.G., Komón, M., et al., 2005. An oligonucleotide barcode for species identification in Trichoderma and Hypocrea. Fung. Genet. Biol., 42(10): 813-828. [doi:10.1016/j.fgb.2005.06.007]

Druzhinina, I.S., Seild-Seiboth, V., Herrera-Estrella, A., et al., 2011. Trichoderma: the genomics of opportunistic success. Nat. Rev. Microbiol., 9(10):749-759. [doi:10.1038/ nrmicro2637]

Feng, X.M., Holmberg, A.I.J., Sundh, I., et al., 2011. Specific SCAR markers and multiplex real-time PCR for quantification of two Trichoderma biocontrol strains in environmental samples. Biocontrol, 56(6):903-913. [doi:10. 1007/s10526-011-9365-7]

Gams, W., Bissett, J., 1998. Morphology and identification of Trichoderma. In: Kubicek, C.P., Harman, G.E. (Eds.), Trichoderma and Gliocladium. Vol. 1. Basic Biology, Taxonomy and Genetics. Taylor \& Francis, UK, p.3-34.

Green, H., Jensen, D.F., 1995. A tool for monitoring Trichoderma harzianum: II. The use of a GUS transformant for ecological studies in the rhizosphere. Phytopathology, 85(11):1436-1440. [doi:10.1094/Phyto-85-1436]

Grondona, I., Hermosa, R., Tejada, M., et al., 1997. Physiological and biochemical characterization of Trichoderma harzianum, a biological control agent against soilborne 
fungal plant pathogens. Appl. Environ. Microbiol., 63(8): 3189-3198.

Hagn, A., Wallisch, S., Radl, V., et al., 2007. A new cultivation independent approach to detect and monitor common Trichoderma species in soils. J. Microbiol. Meth., 69(1): 86-92. [doi:10.1016/j.mimet.2006.12.004]

Harman, G.E., 2006. Overview of mechanisms and uses of Trichoderma spp. Phytopathology, 96(2):190-194. [doi: 10.1094/PHYTO-96-0190]

Harman, G.E., Howell, C.R., Viterbo, A., et al., 2004. Trichoderma species - opportunistic, avirulent plant symbionts. Nat. Rev. Microbiol., 2(1):43-56. [doi:10.1038/nrmicro797]

Hermosa, M.R., Grondona, I., Iturriaga, E.A., et al., 2000. Molecular characterization and identification of biocontrol isolates of Trichoderma spp. Appl. Environ. Microbiol., 66(5): 1890-1898. [doi:10.1128/AEM.66.5.1890-1898.2000]

Hoitink, H.A.J., Boehm, M.J., 1999. Biocontrol within the context of soil microbial communities: a substratedependent phenomenon. Annu. Rev. Phytopathol., 37(1): 427-446. [doi:10.1146/annurev.phyto.37.1.427]

Jessup, C.M., Forde, S.E., Bohannan, B.J.M., 2005. Microbial experimental systems in ecology. In: Desharnais, R.A. (Ed.), Advances in Ecological Research. Elsevier, 37:273-307. [doi:10.1016/S0065-2504(04)37009-1]

Knudsen, I.M., Jensen, B., Jensen, D.F., et al., 1996. Occurrence of Gliocladium roseum on barley roots in sand and field soil. In: Jensen, D.F., Jansson, H.B., Tronsmo, A. (Eds.), Monitoring Antagonistic Fungi Deliberately Released into the Environment. Springer, the Netherlands, p.33-37. [doi:10.1007/978-94-009-1698-2_5]

Komon-Zelazowska, M., Bissett, J., Zafari, D., et al., 2007. Genetically closely related but phenotypically divergent Trichoderma species cause green mold disease in oyster mushroom farms worldwide. Appl. Environ. Microbiol., 73(22):7415-7426. [doi:10.1128/AEM.01059-07]

Koveza, O.V., Kokaeva, Z.G., Gostimsky, S.A., et al., 2001. Creation of a SCAR marker in Pea (Pisum sativum L.) using RAPD analysis. Russ. J. Genet., 37(4):464-466. [doi:10.1023/A:1016627131572]

Kredics, L., Hatvani, L., Naeimi, S., et al., 2014. Biodiversity of the genus Hypocrea/Trichoderma in different habitats. In: Gupta, V.G., Schmoll, M., Herrera-Estrella, A., et al. (Eds.), Biotechnology and Biology of Trichoderma. Elsevier, p.3-24. [doi:10.1016/B978-0-444-59576-8.00001-1]

Kubicek, C.P., Komon-Zelazowska, M., Druzhinina, I.S., 2008. Fungal genus Hypocrea/Trichoderma: from barcodes to biodiversity. J. Zhejiang Univ.-Sci. B (Biomed. \& Biotechnol.), 9(10):753-763. [doi:10.1631/jzus.B0860015]

Lehmann, P.F., Lin, D., Lasker, B.A., 1992. Genotypic identification and characterization of species and strains within the genus Candida by using random amplified polymorphic DNA. J. Clin. Microbiol., 30(12):3249-3254.

Lievens, B., Rep, M., Thomma, B.P.H.J., 2008. Recent developments in the molecular discrimination of formae speciales of Fusarium oxysporum. Pest Manag. Sci., 64(8):781-788. [doi:10.1002/ps.1564]

Martin-Laurent, F., Philippot, L., Hallet, S., et al., 2001. DNA extraction from soils: old bias for new microbial diversity analysis methods. Appl. Environ. Microbiol., 67(5):
2354-2359. [doi:10.1128/AEM.67.5.2354-2359.2001]

Massart, S., de Clercq, D., Salmon, M., et al., 2005. Development of real-time PCR using Minor Groove Binding probe to monitor the biological control agent Candida oleophila (strain O). J. Microbiol. Meth., 60(1):73-82. [doi:10.1016/j.mimet.2004.08.012]

Moore, J.C., Ruiter, P.C., Hunt, H.W., et al., 1996. Microcosms and soil ecology: critical linkages between fields studies and modelling food webs. Ecology, 77(3):694-705. [doi:10.2307/2265494]

Naeimi, S., Kocsubé, S., Antal, Z., et al., 2011. Strain-specific SCAR markers for the detection of Trichoderma harzianum AS12-2, a biological control agent against Rhizoctonia solani, the causal agent of rice sheath blight. Acta Biol. Hung., 62(1):73-84. [doi:10.1556/ABiol.61. 2011.1.8]

Paavanen-Huhtala, S., Avikainen, H., Yli-Mattila, T., 2000. Development of strain-specific primers for a strain of Gliocladium catenulatum used in biological control. Eur. J. Plant Pathol., 106(2):187-198. [doi:10.1023/A: 1008734519852]

Parasnis, A.S., Gupta, V.S., Tamhankar, S.A., et al., 2000. A highly reliable sex diagnostic PCR assay for mass screening of papaya seedlings. Mol. Breed., 6(3):337-344. [doi:10.1023/A:1009678807507]

Pasquali, M., Piatti, P., Gullino, M.L., et al., 2006. Development of a real-time polymerase chain reaction for the detection of Fusarium oxysporum f. sp basilici from basil seed and roots. J. Phytopathol., 154(10):632-636. [doi:10. 1111/j.1439-0434.2006.01160.x]

Pujol, M., Badosa, E., Cabrefiga, J., et al., 2005. Development of a strain-specific quantitative method for monitoring Pseudomonas fluorescens EPS62e, a novel biocontrol agent of fire blight. FEMS Microbiol. Lett., 249(2): 343-352. [doi:10.1016/j.femsle.2005.06.029]

Rozen, S., Skaletsky, H., 1999. Primer3 on the WWW for general users and for biologist programmers. In: Misener, S., Krawetz, S.A. (Eds.), Bioinformatics Methods and Protocols. Springer, p.365-386. [doi:10.1385/1-59259192-2:365]

Rubio, M.B., Hermosa, M.R., Keck, E., et al., 2005. Specific PCR assays for the detection and quantification of DNA from the biocontrol strain Trichoderma harzianum 2413 in soil. Microb. Ecol., 49(1):25-33. [doi:10.1007/s00248003-0171-3]

Savazzini, F., Longa, C.M.O., Pertot, I., et al., 2008. Real-time PCR for detection and quantification of the biocontrol agent Trichoderma atroviride strain $\mathrm{SC} 1$ in soil. $J$. Microbiol. Meth., 73(2):185-194. [doi:10.1016/j.mimet. 2008.02.004]

Savazzini, F., Oliveira Longa, C.M., Pertot, I., 2009. Impact of the biocontrol agent Trichoderma atroviride $\mathrm{SC} 1$ on soil microbial communities of a vineyard in northern Italy. Soil Biol. Biochem., 41(7):1457-1465. [doi:10.1016/j. soilbio.2009.03.027]

Schena, L., Finetti-Sialer, M.M., Gallitelli, D., 2002. Molecular detection of strain L47 of Aureobasidium pullulans, a biocontrol agent of postharvest disease. Plant Dis., 86(1): 54-60. [doi:10.1094/PDIS.2002.86.1.54] 
Schuster, A., Schmoll, M., 2010. Biology and biotechnology of Trichoderma. Appl. Microbiol. Biotechnol., 87(3):787799. [doi:10.1007/s00253-010-2632-1]

van der Putten, W.H., Klironomos, J.N., Wardle, D.A., 2007. Microbial ecology of biological invasions. ISME J., 1(1): 28-37. [doi:10.1038/ismej.2007.9]

Vargas-Gil, S., Pastor, S., March, G.J., 2009. Quantitative isolation of biocontrol agents Trichoderma spp., Gliocladium spp. and actinomycetes from soil with culture media. Microbiol. Res., 164(2):196-205. [doi:10.1016/j. micres.2006.11.022]

Viterbo, A., Haran, S., Friesem, D., et al., 2001. Antifungal activity of a novel endochitinase gene (chit36) from Trichoderma harzianum Rifai TM. FEMS Microbiol. Lett., 200(2):169-174. [doi:10.1111/j.1574-6968.2001. tb10710.x]

White, T.J., Bruns, T., Lee, S.J., et al., 1990. Amplification and direct sequencing of fungal ribosomal RNA genes for phylogenetics. In: Innis, M., Gelfand, D., Shinsky, J., et al. (Eds.), PCR Protocols: a Guide to Methods and Applications. Academic Press, USA, p.315-322. [doi:10.1016/ B978-0-12-372180-8.50042-1]

Williams, J., Clarkson, J.M., Mills, P.R., et al., 2003. A selective medium for quantitative reisolation of Trichoderma harzianum from Agaricus bisporus compost. Appl. Environ. Microbiol., 69(7):4190-4191. [doi:10.1128/AEM. 69.7.4190-4191.2003]
Zhang, F., Zhu, Z., Yang, X., et al., 2013. Trichoderma harzianum T-E5 significantly affects cucumber root exudates and fungal community in the cucumber rhizosphere. Appl. Soil Ecol., 72:41-48. [doi:10.1016/j.apsoil.2013.05.016]

\section{List of electronic supplementary materials}

Fig. S1 Randomly amplified polymorphic DNA (RAPD) fingerprintings of Trichoderma $\mathrm{cf}$. harzianum

Fig. S2 Randomly amplified polymorphic DNA (RAPD) sequence used to design the SCAR primers

Fig. S3 Evaluation of the sequence-characterized amplified region (SCAR) marker primers by polymerase chain reaction (PCR)

Fig. S4 Sequence-characterized amplified region (SCAR) sequence analyses of six Trichoderma cf. harzianum isolates

Fig. S5 Relationships between Trichoderma cf. harzianum isolates using different molecular markers

FASTA S1 Randomly amplified polymorphic DNA (RAPD) sequence based on which the sequence-characterized amplified region (SCAR) primers were designed

FASTA S2 Sequence-characterized amplified region (SCAR) sequences of Trichoderma cf. harzianum isolates

Table S1 BLAST analysis performed to align sequencecharacterized amplified region (SCAR) sequence with different fungal genomes

\section{中文椥要:}

\section{本文题目：SCAR 分子标记监测菌群中的哈茨木䨠}

Designing a SCAR molecular marker for monitoring Trichoderma cf. harzianum in experimental communities

研究目的: 开发具有种属特异性序列特征性扩增区域 (SCAR) 标记物来监测哈茨木霉在其入侵的试验 菌群中的定殖和生长, 为哈茨木霉应用于生物防治等生态和生物技术中提供支撑。

创新要点: 多种木霉属真菌能与各种微观和宏观的生物有机体建立相互作用。利用这些相互作用, 木 霉可做为原生种群的入侵物种而用于生物防治。本文通过使用试验菌群为研究模型, 利用 随机扩增多态性 DNA（RAPD）技术和序列特征性扩增区域（SCAR）标记物来监测菌群中 哈茨木霉的生长状态。

研究方法: 利用随机扩增多态性 DNA (RAPD) 技术, 从16 个 10 聚体引物进行多态性篎选, 其中 1 个引物扩增出对应哈茨木霉的条带。对该条带进行克隆测序, 并设计 5 个 20-23 聚体引物。 成功利用引物对 $2 \mathrm{~F} 2 / 2 \mathrm{R} 2$ 和 $2 \mathrm{~F} 2 / 2 \mathrm{R} 3278$ 分别特异性地扩增出哈茨木霉 BpT10a 菌株 $278 \mathrm{bp}$ 和 $448 \mathrm{bp}$ 的 DNA 片段。同时, 用这两个引物对 14 个哈茨木霉菌株和几种不同的真菌菌株 进行特异性对照试验, 也只成功扩增出哈茨木霉菌株。此外, 使用真菌 DNA 混合物和试验 真菌群的 DNA 为模板, 采用实时聚合酶链式反应 (PCR) 对引物对 $2 F 2 / 2 R 2$ 进行评估。当 仅使用 100 份 SCAR 标记物或哈茨木霉仅占整个菌群的 $0.1 \%$ 时, 仍能检测出哈茨木霉。

重要结论: 本研究所建立的 SCAR 分子标记能有效监测菌群中的哈茨木霉的定殖和生长, 具有较高特 异性、灵敏度和准确度。

关键词组：哈茨木霉；序列特征性扩增区域（SCAR）; 分子标记；试验菌群 